\title{
Human genome deadline cut by two years
}

[WASHINGTON] The main US government sponsor of the Human Genome Project adopted an ambitious plan this week to finish sequencing the human genome by 2003 , two years ahead of the original target.

The advisory council of the National Human Genome Research Institute (NHGRI) unanimously approved the plan, which sets as an interim goal the production by the end of 2001 of a 'working draft' of the genome that is at least 90 per cent complete (see Nature 393, 399; 1998.)

The plan also calls for one-third of the genome to be completely sequenced by 2001 . It calls for a focus on gene-rich regions as this interim goal is reached, and suggests that an international peer review process be set up immediately to prioritize regions to be sequenced, based on the needs of the international research community.

The plan, which sets goals for the entire federal effort between 1999 and 2003, is to be published in full next month. As recently as May, a draft version contained no reference to advancing the target date to 2003.

"We are talking about big and ambitious, even audacious, plans," said Francis Collins, the NHGRI director, at a meeting of the advisory council on Monday (14 September). He described the new targets as "a stretch". But he said the accelerated timetable was vital because every year that passes without the genome sequenced was "an opportunity lost for biomedical research across the board". Collins added: "This is not a time to be conservative, cautious or to coast along."

The new plan will require governmentsponsored sequencers to double or even triple their output. But Collins said that it does not rely on the institute receiving additional funding from Congress beyond regular annual increases "in the neighbourhood of 10 per cent".

To accommodate the new goals, he said, the proportion of the institute's $\$ 218$ million budget spent on sequencing will grow from its current 45 per cent to 60 or 65 per cent by 2001 .

Collins denied that the plan was formulated in reaction to the announcement in May by Celera Genomics, a company headed by genome sequencer J. Craig Venter, that it aims to sequence the genome within three years (see Nature 393, 101; 1998). "This is action, not reaction," said Collins. But he added that the goal of producing a 'working draft' presents "great potential for collaboration" with Celera.

Venter agrees. He calls the government's plan for the draft "a tremendously positive development". It "certainly alleviates any critics' questions or problems about [Celera's] ability to assemble the whole genome".

Celera's plan has been questioned because it relies on the technique of whole genome 'shotgun' sequencing that many predict will present significant reassembly problems. The rapid production of a 'working draft' by the government would provide mapping information of great value to the private reassembly efforts.

David Bentley, head of human genetics at the Sanger Centre in Cambridge, United Kingdom, which will compile one-third of the draft sequence due by 2001, warmly endorsed the new plan, and called the international peer review proposal "excellent". He added: "There is a need to have some sort of process of reviewing all these claims to ensure that the right regions are done, and the best use is made of the resources."

Collins stressed that the 'working draft' was not a "throwaway" product, but an intermediate step to the completion of the genome. "There should be no additional expense created" by its generation, he said.

The Department of Energy has approved the five-year plan. The department, a joint author of the plan, is the other federal sponsor of the genome project. Meredith Wadman

\section{Snowball comet idea refuses to melt away}

[WASHINGTON] Twelve years after two space physicists proposed that Earth is being constantly bombarded by small, watery comets, most scientists are ready to abandon the search for such objects. But at least one observation is still planned to try to confirm or refute their existence.

Louis Frank and John Sigwarth of the University of Iowa, whose controversial claim has been attacked repeatedly in journals and at scientific meetings, still believe house-sized 'snowballs' are entering the atmosphere every few seconds.

Their theory - based on dark spots that showed up in ultraviolet images of Earth taken by the Dynamics Explorer satellite in the early 1980s - appeared vindicated when a second spacecraft, Polar, saw similar spots after its launch in 1996.

Former critics expressed cautious support for the idea, and the director of the US space agency NASA's Goddard Space Flight Center set up a small, informal steering group to help orchestrate attempts to prove or disprove the theory.

Since then, however, a steady stream of evidence has gone against the small comet interpretation. The University of Arizona's Spacewatch asteroid-searching telescope, which should have revealed about 2,000 objects in seven years of scanning the skies, has turned up nothing. Other scientists measuring water vapour in the stratosphere say there is not enough to support the claimed frequency of comet bombardment.

The latest and perhaps most damning refutation is published next month in Geophysical Research Letters. Based on their analysis of a day's worth of raw data supplied by Frank, Forrest Mozer and James McFadden of the University of California at Berkeley conclude that the spots in the Polar images were produced by the instrument and the way in which the data were processed. Frank rejects that interpretation.

But more bad news is on the way. Robert Meier of the US Naval Research Laboratory

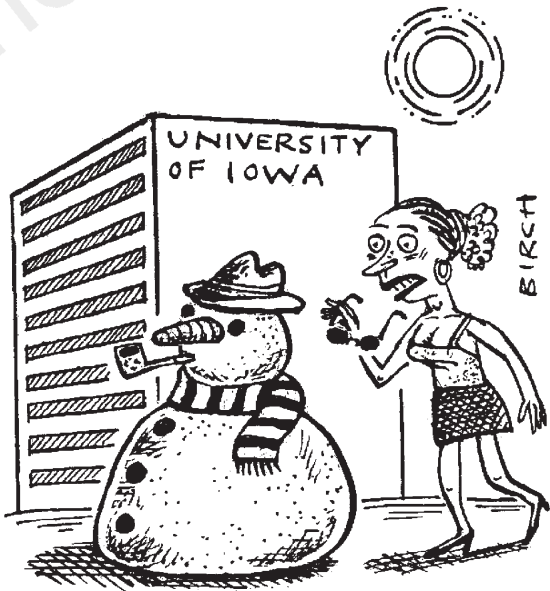

has nearly completed his analysis of data collected by a navy space radar network last autumn. In one six-week period, he says, the radar should have seen tens of thousands of objects. Instead it saw nothing.

Robert Hoffman, the project scientist for Polar and leader of Goddard's small comets steering group, says at least two pieces of evidence have yet to come in. The Spacewatch team has taken 17 images in an observing mode specially designed to capture the objects, if they exist, but has yet to release its analysis.

Hoffman hopes to arrange an independent review of those images, which Frank says should prove his theory. Another team led by John Mathews of Pennsylvania State University, with support from NASA and the National Science Foundation, plans to use the Jicamarca Radio Observatory in Peru to hunt for the objects.

Beyond that, however, few scientists seem interested in pursuing the matter further, and Hoffman is not even sure his steering group will meet again. Although he says there has been no "knockout punch" for the small comets theory, his own group will not attempt a "verdict" one way or the other. "I think the burden of proof is on Frank right now," he says. Tony Reichhardt 